\title{
Bases de datos y literatura ibérica. Aula Ibérica Online / Aula Bilingüe y el corpus de Literatura Hispano-Portuguesa de la Fundación Biblioteca Virtual Miguel de Cervantes Databases and Iberian Literature. Aula Ibérica Online / Aula Bilingüe and the corpus of Spanish-Portuguese Literature of the Fundación Biblioteca Virtual Miguel de Cervantes
}

\section{Pedro Álvarez-Cifuentes}

Universidad de Oviedo, España

\begin{abstract}
Resumen: En complemento a los recursos disponibilizados por el área de Filología Gallega y Portuguesa de la Universidad de Salamanca, el nuevo corpus de Literatura Hispano-Portuguesa de la Fundación Biblioteca Virtual Miguel de Cervantes, dirigido por José Miguel Martínez-Torrejón (Queens College CUNY), ofrece a investigadores y estudiantes universitarios acceso abierto a un amplio catálogo de autores portugueses que escribieron su obra literaria en lengua castellana entre los siglos XVI y XVII y una base de referencias bibliográficas sobre un área generalmente desconocida en el ámbito de las letras peninsulares.
\end{abstract}

Palabras clave: corpus, base de datos, bilingüismo, literatura española, literatura portuguesa

Abstract: In addition to the resources made available by the Galician and Portuguese Philology unit of the University of Salamanca, the new corpus of Spanish-Portuguese Literature of the Fundación Biblioteca Virtual Miguel de Cervantes, led by José Miguel Martínez-Torrejón (Queens College CUNY), provides researchers and university students open access to a wide catalogue of Portuguese authors who wrote their literary works in Spanish between the sixteenth and seventeenth centuries, as well as a bibliographical database concerning a generally unknown area of peninsular literature.

Keywords: corpus, database, bilinguism, Spanish literature, Portuguese literature

Portugueses, castellanos, / non hos quer Deos juntos ver. Garcia de Resende, Cancioneiro Geral

\section{Entre portugueses y castellanos}

Para el estudiante universitario, y también para el especialista, el conocimiento directo de la literatura en lengua española escrita por autores de origen portugués - o viceversa, de la literatura en lengua portuguesa escrita por autores de origen español- no siempre resulta tan sencillo o inmediato como podría parecer a priori. Desde los experimentos lingüísticos que caracterizan las piezas teatrales de Gil Vicente a los tratados de Francisco Manuel de Melo o las notas portuguesas de San Francisco Javier, pasando por los versos compuestos en castellano por sá de Miranda o el propio Luís de Camões, las monografías generalistas y las historias de las literaturas ibéricas tienden a pasar de puntillas por este controvertido apartado 
de las letras peninsulares' ${ }^{1}$ Esto es debido a su difícil adscripción en términos políticos o sesgadamente nacionales y también al problemático acceso a gran parte de los textos, que permanecen inéditos, olvidados o simplemente ignorados por la crítica académica. De igual manera, no abundan en la red las bases de datos informatizadas o los recursos didácticos que profundicen en las relaciones culturales y literarias entre España y Portugal, susceptibles de ser utilizados por los estudiantes de las literaturas románicas. Todo ello a pesar de los considerables puntos de conexión y de los diversos períodos de inevitable confluencia histórica entre ambos territorios, como ocurrió, por ejemplo, entre los siglos XVI y XVII durante la Unión Ibérica (1580-1640) ocasionada por la pérdida del rey D. Sebastião de Portugal en la desastrosa batalla de Alcazarquivir (1578) y el ascenso de la rama española de la Casa de Austria al trono lusitano.

A pesar de las frecuentes tensiones entre portugueses y castellanos, a lo largo de las primeras décadas del siglo XVII -que coinciden, tal vez no por mera casualidad, con el período más esplendoroso de la literatura hispánica, el llamado Siglo de Oro²- aparecen numerosos escritores a ambos lados de la raya ibérica que utilizan tanto el español como el portugués en la composición de sus obras (Vázquez Cuesta, 1988; Buescu, 2000; García Martín, 2008 y 2011). En el mismo sentido, ya apuntaba don Marcelino Menéndez Pelayo en una carta a José María de Pereda que "no hay historia de España sin Portugal; no será completa la historia de nuestra literatura que no abrace, como parte integrante, la portuguesa" (Menéndez Pelayo, 1941: V, 256-257). En este contexto se vuelve necesario, por tanto, replantearnos la relevancia cultural de la literatura hispano-lusa y el abordaje de su estudio en el aula universitaria, a través de las posibilidades que presenta el uso de las nuevas tecnologías de la información y la comunicación.

Sin lugar a dudas, la obra clásica para el estudio de los escritores portugueses que utilizaron el español como lengua literaria es el exhaustivo Catálogo razonado biográfico y bibliográfico de los autores portugueses que escribieron en castellano (1890), del bibliófilo setubalense Domingo Garcia Peres (1812-1902) -corresponsal del propio Menéndez Pelayo y otros eruditos del siglo XIX-. Como apuntábamos, a pesar del éxito relativo de esta primera aproximación bibliográfica a "dos literaturas tan estrechamente unidas que en ellas es más difícil que en los mapas geográficos señalar con exactitud la línea divisoria de cada pueblo" (Peres, 1890: V), los manuales de literatura no han profundizado demasiado en este campo del conocimiento. Ya en pleno siglo XX, los trabajos de José Ares Montes (1956), Antero Vieira de Lemos y Julio Martínez Almoyna (1968) y Eugenio Asensio (1974), así como obras colectivas como las coordinadas por $M^{a}$ Rosa Álvarez Sellers (1999) o por

\footnotetext{
1 "Quizá la situación de una literatura respecto de la otra, en cuanto al sentido de las interinfluencias, esté desequilibrada en favor de la castellana. No tanto, desde luego, como han querido ciertas conclusiones apresuradas e interesadas en demostrar un balance de completa absorción cultural y de prepotente desdén de España hacia Portugal [...] ni tampoco como para quienes defienden la radical autonomía de la personalidad portuguesa" (Bernat Vistarini, 1992: 83).

2 Para Ángel Marcos de Dios (2005: 213), el Siglo de Oro es el período histórico "en el que España mejor comprendió a Portugal".
} 
Francisco Bethencourt (2002), abordan una revisión de esta problemática tan atrayente como escurridiza ${ }^{3}$.

\section{Aula lbérica Online / Aula Bilingüe I y II / BDCLLP}

Una reciente propuesta en este ámbito de investigación de las letras peninsulares fue la aparición de la revista Aula Ibérica Online, dependiente del área de Filología Gallega y Portuguesa de la Universidad de Salamanca. Esta publicación electrónica nació en el marco del proyecto de investigación Arcadia Babélica: usos del castellano, competencias plurilingües y cambio de paradigmas identitarios en las academias portuguesas del Antiguo Régimen (referencia: FFI2009-07451) y está disponible en abierto en la página web <http://www.filologiaportuguesa.es/aulalbericaActual.asp>. Tras el notable éxito de los congresos luso-hispánicos celebrados en las Universidades de Évora y Salamanca entre 2006 y 2007 (Marcos de Dios, 2007), los responsables de Aula Ibérica Online se proponían "sedimentar y proyectar en el tiempo un espacio de reflexión crítica sobre la amplia y compleja fenomenología de los intercambios lingüísticos y culturales entre el mundo lusófono (Portugal, Brasil, PALOPs) y el mundo hispanófono, tanto en la actualidad como en el pasado". Los objetivos concretos de esta publicación se proponían: i) la "construcción de modelos hermenéuticos congruentes y que respondan a los desafíos de los desarrollos actuales de los estudios lingüísticos, literarios y culturales"; ii) la "proyección pública y socialización del conocimiento producido en estos ámbitos disciplinares".

En el primer número $-y$, lamentablemente, único por el momento- de Aula Ibérica Online, aparecido en 2010, Ángel Marcos de Dios (2010) elaboraba un interesante catálogo de obras de autores portugueses que circularon en España durante los siglos XVI y XVII; Eduardo Javier Alonso Romo (2010) investigaba la expresión en lengua castellana de los agustinos presentes en Portugal entre 1550 y 1700; y, por último, Pedro Serra (2010) analizaba precisamente los fundamentos teóricos de la obra bibliográfica de Domingo Garcia Peres en el contexto del iberismo ideológico del siglo XIX. El número se cierra con una reseña del volumen colectivo editado por Anxo Abuín González y Anxo Tarrín Varela bajo el título Bases metodolóxicas para unha historia comparada das literaturas da península Ibérica (2004). Asimismo, el proyecto "Arcadia Babélica" se vio culminado con la publicación de dos volúmenes del monográfico Aula Bilingüe -el primero (Marcos de Dios, 2008) subtitulado "Investigación y archivo del castellano como lengua literaria en Portugal"4 y el segundo (Marcos de Dios, 2012) "Usos del castellano y competencias plurilingües en el sistema interliterario peninsular"-, que contaron con la participación de especialistas en la materia como Ana Ma García Martín, Ángel Marcos de Dios, Carlos Reis, Eduardo Javier Alonso Romo, Jorge Fernandes da Silveira, Luciana Villas Boas, Marcello Moreira, Marcia Arruda Franco, Marie Roig Miranda, Pedro Serra, Rafael Valladares, Vanda Anastácio, Vítor Aguiar e Silva, Zulmira Santos e Inês Nemésio.

\footnotetext{
3 Pueden consultarse también los trabajos pioneros de Sousa Viterbo (1891 y 1915) y la monografía de García Gil (1989), que rastrea de manera paralela la presencia de libros españoles en las bibliotecas portuguesas.

${ }^{4}$ El primer número de Aula Bilingüe contó con una segunda edición aumentada en 2014.
} 
Desde 2008, el área de Filología Gallega y Portuguesa de la Universidad de Salamanca también pone a disposición del usuario a través de la página web <http://www.estudiosportugueses.es> una "Base de Datos del Castellano como Lengua Literaria en Portugal" (en mención abreviada: BDCLLP)5, surgida en el marco del proyecto anterior El castellano como lengua literaria en Portugal (referencia: HUM2005-01988). Esta base de datos cuenta con una sencilla interfaz en la que se pueden realizar búsquedas a través de categorías como "autor", "título", "lugar de publicación", "impresor o editor", "datación", "perfil temático" o "palabras clave", entre otros. Las fichas digitales disponibles ofrecen datos de gran interés para la descripción codicológica de los documentos y su ubicación física. Se trata, sin duda, de una eficaz herramienta informática que "permite estudiar la deriva del uso del castellano, por una parte, y la deriva de las competencias plurilingües, por otra, en la mutación de los espacios de acción comunicativa de los siglos áureos" (Marcos de Dios, 2012: 6).

\section{El corpus de Literatura Hispano-Portuguesa de la Fundación Biblioteca Virtual Miguel de Cervantes: descripción y utilidades}

Como complemento a estos recursos, la Fundación Biblioteca Virtual Miguel de Cervantes inauguró el pasado mes de septiembre de 2015 un novedoso proyecto dedicado exclusivamente al estudio de la literatura hispano-lusa escrita entre los siglos XVI y XVII. La Biblioteca Hispano-Portuguesa está disponible en acceso abierto en el repositorio digital denominado "Cervantes Virtual", en la página web $<$ http://www.cervantesvirtual.com/portales/literatura hispanoportuguesa>. El portal temático está dirigido por el profesor José Miguel Martínez-Torrejón (Queens College CUNY, Hispanic Languages and Literatures), reconocido especialista en el campo de los estudios ibéricos y principal promotor de esta valiosa iniciativa.

La Biblioteca Virtual Miguel de Cervantes, dependiente de la Fundación Biblioteca Virtual Miguel de Cervantes, constituye un inventario virtual de obras clásicas de las diferentes lenguas hispánicas, que se presentan en un formato que facilita su impresión y posterior utilización en el aula. Dispone de un sistema de ordenación y búsqueda similar al de una biblioteca presencial y posibilita el acceso gratuito a los materiales desde cualquier lugar del mundo a través de internet. Desde su creación en 1998, se ha consolidado como un espacio de referencia en el estudio de las culturas hispánicasb. Como se indica en <http://www.cervantesvirtual.com/marco-legal/>,

la Biblioteca Virtual Miguel de Cervantes, como centro de investigación en tecnologías de la información y la comunicación aplicados a la edición

\footnotetext{
5 Para más detalles sobre el proceso de creación y diseño de la "Base de Datos del Castellano como Lengua Literaria en Portugal" (BDCLLP), véase el artículo de Serra (2008).

6 Según figura en su página web, "en febrero de 2013 la Biblioteca Virtual Miguel de Cervantes obtuvo el Premio Stanford para la Innovación en Bibliotecas de Investigación (SPIRL), galardón que compartió con la Biblioteca Nacional de Francia. Según el jurado, la Cervantes mereció el reconocimiento por sus contenidos de primera calidad, entre los que destacan sus ediciones críticas integrales, utilizadas por la comunidad investigadora mundial. La organización subrayó que la Cervantes abordaba los retos de las bibliotecas digitales mediante un diseño abierto y enfocado a los usuarios, con una arquitectura orientada a ofrecer servicios y un soporte de desarrollo en código abierto". Véase <http://fundacion.cervantesvirtual.com/presentacion/>.
} 
digital, bibliotecas digitales y humanística, ha desarrollado diversas herramientas tecnológicas tales como buscadores especializados y herramientas lingüísticas-concordancias, diccionarios, ...- que pueden estar a disposición del usuario en el presente portal.

Actualmente, la Biblioteca Virtual Miguel de Cervantes integra más de 550 portales dedicados a autores fundamentales de las lenguas hispánicas, instituciones académicas y áreas temáticas de tipo muy diverso (Lengua, Literatura, Historia, Biblioteca Americana, Biblioteca de Signos, Biblioteca Joan Lluís Vives, Biblioteca Letras Galegas, Literatura Infantil y Juvenil, etc.), además de ofrecer una base de datos que supera los 195.000 registros bibliográficos ${ }^{7}$. Asimismo, cuenta con un servicio interactivo denominado "El Bibliotecario", que permite al visitante solicitar informaciones de tipo bibliográfico o documental, plantear dudas sobre los fondos y el funcionamiento de la Biblioteca Virtual, comunicar problemas técnicos, sugerir mejoras o, incluso, proponer la inclusión en el catálogo de nuevas obras.

De esta manera, el corpus de Literatura Hispano-Portuguesa de la Fundación Biblioteca Virtual Miguel de Cervantes propone el acceso abierto a un extenso catálogo de autores portugueses que escribieron su obra literaria en lengua castellana -antes, durante y después de la Unión Ibérica entre 1580 y 1640-, así como un amplio abanico de referencias bibliográficas sobre el tema, al alcance tanto del alumno como del investigador especializado. Para el desarrollo de este ambicioso inventario, la Biblioteca Virtual Miguel de Cervantes ha contado con la colaboración de prestigiosas instituciones internacionales tales como la Biblioteca Nacional de Portugal, la Fundação Calouste Gulbenkian, la Biblioteca de Catalunya, la Bayerische Staatsbibliothek de Múnich, la New York Public Library, la Biblioteca Nazionale Centrale de Roma, las universidades de Oxford, Michigan, Barcelona, Sevilla, Lisboa y Oporto y la plataforma virtual Google Books, que han aportado desinteresadamente reseñas, documentos y textos digitalizados.

El corpus de Literatura Hispano-Portuguesa de la Fundación Biblioteca Virtual Miguel de Cervantes se divide actualmente en los siguientes apartados, con una clara organización interna:

1) En primer lugar figura la "Presentación" del responsable del proyecto, el profesor José Miguel Martínez-Torrejón (Queens College CUNY), que introduce la problemática intrínseca del estudio de la literatura hispano-lusa y expresa su intención de "dar mayor difusión a un corpus que se extiende por todos los géneros literarios y que con frecuencia ha caído en el limbo de historiadores e investigadores debido a la configuración nacionalista de la historia de la literatura, en que un determinado territorio nacional o estatal queda asociado a la cultura de una lengua". Este texto preliminar aparece convenientemente acompañado de la reproducción de un bodegón de la pintora barroca hispano-portuguesa Josefa de Ayala Figueira (1630-1684), más conocida como Josefa de Óbidos.

2) A continuación, en la "Introducción", José Miguel Martínez-Torrejón traza un breve panorama de la literatura hispano-portuguesa, contextualizada en clave

\footnotetext{
7 En 2014 sirvió 24.5 millones de páginas y registró un incremento del $29.3 \%$ del número de visitas, alcanzando los 6.746 .500 visitantes únicos, lo que representa un aumento del $32.78 \%$ (<http://fundacion.cervantesvirtual.com/presentacion/>).
} 
cronológica, desde las tempranas coplas en castellano del condestable D. Pedro de Portugal (1429-1466) y las modas cortesanas de los reinados de D. Manuel I y D. João III -el "gran siglo del bilingüismo ibérico"8- hasta la relativa decadencia literaria durante la monarquía dual y las nuevas esperanzas depositadas en la Restauración de la Independencia de 1640. Martínez-Torrejón revisa la actividad literaria de figuras esenciales como Garcia de Resende, Gil Vicente, Francisco de Sá de Miranda, Jorge de Montemayor, Diogo Bernardes, Luís de Camões, Pero de Andrade Caminha, Francisco da Costa, Jerónimo de Corte-Real, Francisco Monzón, Bernarda Ferreira de Lacerda, Jacinto Cordeiro, João Soares de Alarcão, Francisco Rodrigues Lobo, Soror Violante do Ceu, Francisco Galvão, Mariana de Luna, Miguel da Silveira, Francisco de Portugal, Manuel de Faria e Sousa, Francisco Manuel de Melo, Manuel de Gallegos, Soror Maria do Céu, Matias Pereira da Silva y Francisco de Vasconcelos, entre muchos otros escritores portugueses en lengua española. La mención de cada autor contiene un hipervínculo que permite acceder directamente a una ficha digital con información detallada sobre su vida y su obra.

3) La búsqueda en el "Catálogo" de los textos disponibles en línea generalmente en formato pdf o html- puede activarse a partir del nombre y apellidos del autor o del título de la obra en cuestión. La herramienta, muy intuitiva, permite acceder a los distintos materiales en función de la demanda del usuario, que solo tiene que introducir en el buscador el tema de su interés para que los documentos relacionados le aparezcan ordenados alfabéticamente en la pantalla, mediante un sencillo sistema en el que es posible filtrar los resultados con las opciones de "autor", "título" o "materia".

4) El apartado "Hemeroteca" permite al visitante del portal acceder a varios números de las publicaciones periódicas Península. Revista de Estudos Ibéricos (editada por el Instituto de Estudos Ibéricos de la Faculdade de Letras da Universidade do Porto desde 2003, con 7 tomos) y La Ilustración Ibérica, un "semanario científico, literario y artístico" que apareció en Barcelona entre 1883 y 1898 y que estaba "redactado por los más reputados escritores de España y Portugal e ilustrado por los mejores artistas del universo". La Ilustración Ibérica publicó un total de 730 números, y en su cabecera aparecían los retratos de Camões, Cervantes y Homero. Confiamos en que esta selección de revistas sea ampliada en el futuro por los responsables del portal.

5) La sección "Estudios" brinda la posibilidad de acceder a diferentes obras monográficas dedicadas al estudio de la literatura hispano-portuguesa del Renacimiento y el Barroco. Si bien el fondo de recursos que ofrece este apartado todavía es escaso, el portal facilita la consulta de los trabajos de renombrados especialistas en el área como $M^{a}$ Rosa Álvarez Sellers, Joan Estruch Tobella, Maria de Lurdes Correia Fernandes y Rita Marnoto.

6) La "Bibliografía" pone a disposición del investigador un abundante catálogo de referencias bibliográficas, fuentes primarias y secundarias, organizadas en tres secciones principales: "Autores particulares" (67 entradas), "Obras colectivas de contenido poético bilingüe" (16 entradas) y "Estudios" (62 entradas). Aún lejos de

\footnotetext{
8 "Da rapidez com que se incrementa o uso do castelhano por parte dos autores portugueses ao longo do século XVI dão conta os catálogos 'castelhanizantes' com que contamos, obras que, ainda que incompletas e imprecisas, permitem avaliar a magnitude e progressão do fenómeno. Da análise desses catálogos [...], conclui-se que só nesse século o número de escritores portugueses que recorre à língua castelhana aproxima-se das duas centenas" (García Martín, 201 1: 76).
} 
tener un carácter exhaustivo, esta base bibliográfica también se encuentra en permanente estado de expansión y actualización.

7) Finalmente, la sección "Imágenes" proporciona una serie de recursos visuales y pictóricos que pueden ser utilizados como complemento didáctico en la enseñanza de la literatura hispano-portuguesa de los siglos XVI y XVII. La primera galería disponible, titulada "Personajes" (con 19 elementos), incluye retratos de las principales figuras históricas del período, como por ejemplo los reyes D. Manuel I, D. João III, D. Sebastião, D. João IV, D. Afonso VI y D. Pedro II de Portugal; los monarcas españoles Felipe II, Felipe III y Felipe IV; las reinas doña Isabel y doña María de Aragón, doña Leonor y doña Catalina de Austria y doña Luisa Francisca de Guzmán; y otros personajes contemporáneos como el archiduque Alberto de Austria, virrey de Portugal entre 1583 y 1593, o el pretendiente al trono D. António, prior de Crato. La segunda galería, "Grabados" (con 4 elementos), propone un conjunto de imágenes sobre el aspecto de la ciudad de Lisboa durante los Siglos de Oro, mucho antes del devastador terremoto de 1755 que modificó para siempre su geografía urbana. Por último, el apartado "Lugares" (con 10 elementos) ofrece diversas imágenes de monumentos y enclaves emblemáticos para el estudio de la cultura portuguesa, como el monasterio de los Jerónimos y el monasterio de $\mathrm{S}$. Vicente de Fora (ambos en Lisboa); las Universidades de Évora y Coimbra; y el palacio de los duques de Bragança en Vila Viçosa. Indudablemente, todos estos recursos visuales -que serán incrementados progresivamente- enriquecen el conocimiento integral de una época tan apasionante como compleja.

8) A modo de cierre, un listado de enlaces a las páginas web de instituciones de gran renombre en el ámbito de los estudios lusófonos -tales como la Academia das Ciências de Lisboa, la Biblioteca Nacional de Portugal o la Fundação Calouste Gulbenkian- completa el abanico de recursos que ofrece el portal temático y favorece, sin duda, la difusión internacional y la visibilidad de sus contenidos, además de fomentar las investigaciones de tipo interdisciplinar.

\section{Conclusiones: nuevas herramientas para el estudio de las literaturas ibéricas}

Para Ana Ma García Martín (2011: 78), "a dimensão que o fenómeno do bilinguismo Iuso-castelhano assume na literatura portuguesa é extraordinária, tanto pela quantidade como pela qualidade dos autores portugueses que escreveram toda ou parte da sua obra em castelhano". El estudio pormenorizado de esta literatura bilingüe se ha vuelto absolutamente necesario para comprender de manera global la cultura hispánica de los Siglos de Oro. Asimismo, la introducción de las nuevas tecnologías de la información y la comunicación en el aula y el acceso a catálogos y repertorios digitales han supuesto un notable avance en este campo de conocimiento. En complemento a los valiosos materiales disponibilizados por el área de Filología Gallega y Portuguesa de la Universidad de Salamanca -como Aula Ibérica Online y Aula Bilingüe, o la "Base de Datos del Castellano como Lengua Literaria en Portugal" (BDCLLP)-, el corpus de Literatura Hispano-Portuguesa de la Fundación Biblioteca Virtual Miguel de Cervantes agiliza el acceso a documentos literarios y lingüísticos de gran interés y utilidad para el investigador. Como razonaba Pedro Serra (2008: 171) respecto a la BDCLLP:

Não é dispiciendo, antes pelo contrário, o facto de o arquivo digital, precisamente por ser produzido no meio digital, permitir a publicação e 
acesso em aberto de material bibliográfico e documentos cujos custos de impressão, difusão e acesso se vêm reduzidos.

Las mismas consideraciones son aplicables a este nuevo corpus de Literatura Hispano-Portuguesa, que se propone entre sus objetivos favorecer el intercambio científico y la colaboración entre estudiantes, docentes e investigadores internacionales. El inventario de datos bibliográficos -así como el rico apoyo iconográfico que incluye la plataforma, en permanente desarrollo- puede ser empleado en la clase de literatura áurea y literatura comparada, al poner a disposición del usuario una amplia gama de recursos sobre textos de tipo muy variado. Si bien el portal es muy reciente y existen diversos apartados que merecerían ser expandidos o actualizados en el futuro, su aparición constituye una excelente noticia para los especialistas 0 , simplemente, para los curiosos que quieran descubrir la literatura hispano-portuguesa de los siglos XVI y XVII.

\section{Bibliografía}

ABUÍN GONZÁLEZ, A. \& A. TARRÍO VARELA (eds.) (2004): Bases metodolóxicas para unha historia comparada das literaturas da península Ibérica. Santiago de Compostela: Universidade de Santiago de Compostela.

ALONSO ROMO, E. J. (2010): "Agustinos portugueses que escribieron en castellano (1550-1700)". Aula Ibérica Online, 1, pp. 58-94.

ÁLVAREZ SELLERS, M. R. (ed.) (1999): Literatura portuguesa y literatura española: influencias y relaciones. Valencia: Publicacions de la Universitat de València.

ARES MONTES, J. (1956): Góngora y la poesía portuguesa del siglo XVII. Madrid: Gredos.

ASENSIO, E. (1974): Estudios Portugueses, París, Fundação Calouste Gulbenkian.

BERNAT VISTARINI, A. (1992): Francisco Manuel de Melo (1608-1666). Textos y contexto del Barroco peninsular. Palma: Universitat de les Illes Balears - Servei de Publicacions i Intercanvi Científic.

BETHENCOURT, F. (dir.) (2002) : La littérature d'auteurs portugais en langue castillane. Lisboa; París: Centro Cultural Calouste Gulbenkian.

BUESCU, A. I. (2000): "Y la hespañola es fácil para todos: O bilinguismo, fenómeno estrutural (séculos XVI-XVIII)". Memória e poder. Ensaios de História Cultural (séculos XV-XVIII). Lisboa: Cosmos, pp. 51-66.

GARCÍA GIL, H. (1989): Livros Quinhentistas Espanhóis da Biblioteca da Academia das Ciências de Lisboa. Lisboa: Academia das Ciências de Lisboa.

GARCÍA MARTíN, A. M. (2008): "El bilingüismo luso-castellano en Portugal: estado de la cuestión". Aula Bilingüe I: Investigación y archivo del castellano como lengua literaria en Portugal. Á. MARCOS DE DIOS (ed.). Salamanca: LusoEspañola de Ediciones, pp. 15-44.

- (201 1): "Bilinguismo literário luso-castelhano no tempo de Camões". Dicionário de Luís de Camões. V. AGUIAR E SILVA (org.). Lisboa, Caminho, pp. 75-80.

LEMOS, A. VIEIRA DE \& J. MARTíNEZ ALMOYNA (1968): La lengua española en la literatura portuguesa. Madrid: Imnasa.

MARCOS DE DIOS, Á. (2005). "Viaje del Siglo de Oro a la cultura portuguesa". Territórios e Culturas Ibéricas. Porto: Campo das Letras, pp. 213-223. 
- (coord.) (2007): Aula Ibérica. Actas de los congresos de Évora y Salamanca. Salamanca: Ediciones de la Universidad de Salamanca.

- (ed.) (2008): Aula Bilingüe I: Investigación y archivo del castellano como lengua literaria en Portugal. Salamanca: Luso-Española de Ediciones.

- (2010): "Libros y lecturas portuguesas en la España de los siglos XVI y XVII". Aula Ibérica Online, 1, pp. 1-57.

- (ed.) (2012): Aula Bilingüe II: Usos del castellano y competencias plurilingües en el sistema interliterario peninsular. Salamanca: Luso-Española de Ediciones.

MENÉNDEZ PELAYO, M. (1941): Estudios y discursos de crítica histórica y literaria, edición de Enrique Sánchez Reyes. Madrid: Aldus.

PERES, D. Garcia (1890): Catálogo razonado biográfico y bibliográfico de los autores portugueses que escribieron en castellano. Madrid: Imprenta del Colegio Nacional de Sordomudos y Ciegos.

SERRA, P. (2008): "Funções sociais da competência plurilingue nos séculos áureos peninsulares". Aula Bilingüe l: Investigación y archivo del castellano como lengua literaria en Portugal. Á. MARCOS DE DIOS (ed.). Salamanca: LusoEspañola de Ediciones, pp. 139-208.

SERRA, P. (2010): "O Catálogo Razonado de Garcia Peres na Companhia do Império". Aula Ibérica Online, 1, pp. 95-108.

VITERBO, F. Marques de Sousa (1891): Poesias de Auctores Portuguezes em livros de Escriptores Hespanhoes. Resenha Bibliographica. Coimbra: Imprensa da Universidade.

- (1915): A Literatura Hespanhola em Portugal. Lisboa: Imprensa Nacional.

VÁZQUEZ CUESTA, P. (1988): A Língua e a Cultura Portuguesas no Tempo dos Filipes. Mem Martins: Publicações Europa-América.

\section{Sitografía}

Aula Ibérica Online: <http://www.filologiaportuguesa.es/aulalbericaActual.asp>. Consultado el 26/02/2016.

Base de Datos del Castellano como Lengua Literaria en Portugal (BDCLLP): <http://www.estudiosportugueses.es>. Consultado el 26/02/2016.

Corpus de Literatura Hispano-Portuguesa:

<http://www.cervantesvirtual.com/portales/literatura_hispanoportuguesa>. Consultado el 26/02/2016.

Fundación Biblioteca Virtual Miguel de Cervantes: <http://fundacion.cervantesvirtual.com>. Consultado el 26/02/2016. 